\title{
Role of nurses in health needs of refugees and Internally Displaced Peoples
}

\author{
Hawar Abdulrazaq Mohammedsadiq; Department of Nursing, College of Nursing, University Of Duhok, Duhok, \\ Iraq. (Correspondence: hawar.abdulrazaq@gmail.com )
}

Sana Thannon Ahmed; Department of Nursing, College of Nursing, University Of Duhok, Duhok, Iraq. Saadia Kadhim MuhammedHassan; Duhok General Directorate of Health, Duhok, Iraq.

\section{ABSTRACT}

Background and objectives: Nurses working in refugee camps face to high basic health needs of these populations requiring a nursing role in this situation. The aim of this study was to explore the role of nurses in addressing the basic health needs of refugees and internally displaced peoples.

Methods: In this cross-sectional study, 120 nurses from 26 camps in Duhok governorate/ Iraqi Kurdistan were invited to participate in the study between September 15th and November 25th, 2017. Data was collected through the direct interview (investigatoradministered self-reported technique) with the participants. The findings of the study were presented in descriptive statistics.

Results: The mean age of nurses was 29.10 years old. The nurses participated in activities such as infection control activities (78.3\%), health education campaigns (92.5\%), breastfeeding education (84.2\%), and nursing health care services (94.2\%). Board of Relief and Humanitarian Affairs is a governmental body within the structure of Duhok governorate and is a key agent of basic needs of refugees.

Conclusions: The study documented that a considerable percentage of nurses have participated in the nursing-based activities in refugee camps.

Keywords: Refugee, Internally Displaced People, Nurse, Role, Health needs

$\begin{array}{lll}\text { Received: 30/10/2018 Accepted: 25/2/2019 Published: 30/5/2019 } & \text { Act }\end{array}$

\section{INTRODUCTION}

There has been a dramatic increase in the number of Internally Displaced Peoples (IDPs) in recent years in Iraq. Therefore, nurses working in the residential areas of these people face a high health need in corresponded health settings. Displaced people and refugees are involuntary migrants forced by extraordinary situations to leave their homes and/or countries of residence to find safe places [1]. The United Nations defines a "refugee" as "any person who, owing to a well-founded fear of being persecuted for reasons of race, religion, nationality, membership or particular social group, or political opinion, is outside the country of his nationality, and unable to or, owing to such fear, is unwilling to avail himself of the protection of that country" [2].

Refugees face severe public health deficiencies as a result of poor sanitation of potable water which serves as one of the primarily responsible factors for mortality and morbidity [3]. The United Nations High Commissioner for Refugees (UNHCR) reported that 59.5 million persons were forcibly displaced across the world due to persecution, conflict, violence, or human rights violations by the end of 2014 [4].

Infectious diseases are very common 
among refugees and IDPs. However, many of these diseases are preventable by establishing safe water practices such as sewage waste management and improved personal and water health practices as reflected in the World Health Organization (WHO) task force [5].

The Kurdistan region is a federal state inside Iraq that has faced a growing number of Internally Displaced Peoples (IDPs) and Syrian refugees for the past four years. In 2012, there was an unprecedented rise in the number of IDPs and refugees which has overburdened the local health-care system. As a result, it seems that numbers are not going to be reduced considerably. According to the Board of Relief and Humanitarian Affairs (BRHA), 144,181 families consisted of 738,494 individuals lived in 27 camps in Duhok geographic areas until the end of October 2017 [6].

Nurses can play an important role in identifying and addressing early basic health needs in refugees. Refugees present unique opportunities and challenges for the nursing profession [7].

There is limited research on infectious disease and the lack of basic health needs among IDPs and refugees in this region. The nurses provided health services to 75,274 patients including IDPs and host communities in local health facilities from August 9th, 2014 through June 2015, according to the BRHA [6]. However, to the authors' knowledge, the role of nurses in addressing the basic health needs of refugees has not been explored in this region.

Refugees and displaced people have a mortality rate of over 60 -fold during the acute phase of forced migration and settlement in the camps. The spread of communicable diseases is responsible for over threequarters of these deaths [8]. Nurses as a part of the health care team can play a key role in infection control in these emergency situations.

The aim of this study was to explore and examine the role of nurses in addressing basic health needs of refugees and IDPs, specifically focusing on infection control, health education, and breastfeeding education in Duhok Governorate in Kurdistan Region-Iraq in 2017.

\section{METHODS}

\section{Study design and sampling methods}

This cross-sectional study was based on a purposive sample including 120 nurses in 26 of 27 IDPs/refugee camps across Duhok governorate in September 2017. Only one camp was not recruited in this study due to its distance from the city center. The available and accessible nurses in the selected camps were invited to partake in the current study regardless of their gender, age, and other socio-demographic characteristics following taking official permission from their corresponding administrative and executive organizations. Participation in the study was completely voluntary.

The Internally Displaced Peoples are people displaced from Ninewa governorate, including Mosul city, Neinewa Plain, Zummar, and Sinjar areas since August 2014 due to the conflict, violence, and atrocities applied by the Islamic State in Iraq and Syria (ISIS) in the occupied areas. The majority of displaced persons live in urban areas, including cities, towns and residential complexes in Duhok provinces and enjoy available health and social infrastructure such as water, electricity, housing, fuel, security, traffic, waste collection services, shopping centers just as province citizens do.

Data required for the present study included socio-demographic information and nursing-related practices were collected via interview. This study required information regarding gender, education level, 
age, experience in nursing by month, and nursing-related practices measured in binary responses. These responses were collected through the direct interview with nurses over the course of fifteen field trips from September through November 2017. In addition, information on BRHA activities and its services were obtained through visiting their main office in Duhok and their website.

The BRHA is a governmental body within the structure of Duhok governorate established in 2015. It is the main operational counterpart of United Nations (UN) agencies, humanitarian organizations, health and non-health service providers to those persons who have left their hometowns from other regions of Iraq and Syria since 2014 following ISIS' invasion. BRHA's main concern is to provide the humanitarian assistance to IDPs, refugees, returnees and host communities by establishing cooperation with UN agencies, non-governmental humanitarian organizations, governmental partners, camp management strategies, and community mobilization [6].

BRHA as the main governmental entity of the humanitarian department in Duhok takes into consideration: on camp management; basic services, including water, sanitation, shelter, health, education, and municipal services; social and community services; and capacity building.

\section{Basic health infrastructure in IDPs/refugee} camps

Of the total 248,000 refugees registered in Iraq, close to $97 \%$ of them were settled temporarily in Kurdistan. Duhok, being a governorate in close to Syria, has accepted a significant percentage of Syrian refugees thus creating a heavy burden for the local government and Non-Governmental Organization (NGOs) in the camps for their basic health services. Duhok governorate and Kurdistan Regional Government (KRG) have allocated a budget annually for infrastructure and basic services to the Syrian refugees in and outside camps such as water, shelter, health sanitation, and education. Until 2016, 514,499 refugees lived in Duhok governorate inside camps and host communities [6].

\section{Demographic composition in Duhok Camps}

The IDPs consist of majority Muslim populations, including Kurds, Turkmen, and Arabs with a few Christian families and a considerable percentage of Yezidi Kurds (82.3\% of camps inhabitants) displaced from Sinjar, Zumar, and Ninewa Plain following ISIS invasion.

As of 2016, of the total 23 IDPs camps in Duhok, the medical services to IDPs camps were provided by 78 physicians, 119 nurses, 32 pharmacists, 12 dentists, 25 PHCs, 15 ambulances, 19 pharmacies, 2 delivery rooms, 7 dental clinics, and 12 medical laboratories. On average, 3,000 patients visit these health centers. Common causes of patients' consultation are respiratory infections, skin infections, and urinary tract infections [6].Verbal consent was taken from all nurses before data collection guaranteeing the confidentiality of all personal information. The Scientific Research Division/Department of Planning/Duhok General Directorate of Health in Duhok/Iraqi Kurdistan approved the study protocol. The descriptive purposes of the study were addressed through the frequency percentage or mean standard deviation. The SPSS version 23 was used for statistical calculations.

\section{RESULTS}

120 nurses participated in the present study, with more than half of them identifying as female $(53.3 \%)$ and most nurses graduated high school $(41.7 \%)$ and nursing institute (40.8\%) with a median experience of 56.50 months and mean age of 20.10 years old (Table 1 ). 
Table 1: Demographic characteristics of nurses working in refugee and IDP camps

\begin{tabular}{lcc}
\hline \multirow{2}{*}{ Nurses' Characteristics ( $\mathbf{n = 1 2 0 )}$} & \multicolumn{2}{c}{ Frequency Distribution } \\
\cline { 2 - 3 } & $\mathbf{F}$ & $\%$ \\
\hline Gender & 56 & 46.7 \\
$\quad$ Male & 64 & 53.3 \\
Female & & \\
Education & 50 & 41.7 \\
High School Graduate & 49 & 40.8 \\
Institute Graduate & 21 & 17.5 \\
Bachelor & 46.50 & 78.75 \\
Nurses' Experience (month); Median/ Interquartile range & 29.10 & 12.90 \\
Age (year); Mean/SD & & \\
\hline
\end{tabular}

The study showed that majority of the nurses had an active participation in infection control activities, including oral polio vaccine (OPV) administration to the refugee/IDPs (85.8\%), HBV vaccination during the first hours of the refugee arrival to camp (34.2\%), tetanus vaccination administration to women (52.5\%), and participation in infection control campaigns inside the camps (78.3\%) (Table 2).

Regarding refugee/IDP health education in these camps, the results showed that the majority of them have participated in health education programs with activities such as personal hygiene, disease prevention, hand washing, and women's health (92.5\%).
Similarly, more than two-thirds of the nurses have visited the refugee/IDPs tents for the health education purposes (68.3\%) and most the nurses (84.2\%) have educated women on breastfeeding education (Table 3).

Nursing care, including wound dressing, injection, and fracture maintenance, and general first aid services were presented by $94.2 \%$ and $95.8 \%$ of nurses, respectively. However, a small percentage of the nurses have participated in providing obstetric services to women in the camps (26.7\%) (Table 4).

Table 2: Nursing role in infection control among refugee and IDPs in Duhok

\begin{tabular}{lll}
\hline & \multicolumn{2}{c}{ Frequency Distribution } \\
Infection control activities of nurses in camps $(\mathbf{n}=\mathbf{1 2 0})$ & \multicolumn{2}{c}{$\mathbf{F}(\%)$} \\
\cline { 2 - 3 } & Yes & $17(14.2)$ \\
\hline Giving OPV vaccination upon refugee registration in camp & $103(85.8)$ & $79(65.8)$ \\
HBV vaccination during the first hours of arrival to camp & $41(34.2)$ & $57(47.5)$ \\
Administrating Tetanus vaccination to women in camp & $63(52.5)$ & $26(21.7)$ \\
Participating in campaigns of communicable disease control & $94(78.3)$ & \\
\hline
\end{tabular}

Table 3: Role of nurses in health education to refugees/IDPs in camps

\begin{tabular}{lll}
\hline \multirow{2}{*}{ Health education of nurses to refugee/IDPs in camps $(\mathbf{n = 1 2 0 )}$} & \multicolumn{2}{l}{ Frequency Distribution* } \\
\cline { 2 - 3 } & Yes & No \\
\hline $\begin{array}{l}\text { Health education, including personal hygiene, disease prevention, } \\
\text { hand washing, women's' health }\end{array}$ & $111(92.5)$ & $9.5)$ \\
$\begin{array}{l}\text { Home visit strategies for health education purposes } \\
\text { Breastfeeding education to women }\end{array}$ & $82(68.3)$ & $38(31.7)$ \\
\hline
\end{tabular}


Table 4: Role of nurses in providing nursing care to refugees/IDPs in camps

\begin{tabular}{lll}
\hline \multirow{2}{*}{ Nursing care provision to refugee/IDPs in camps $(\mathbf{n = 1 2 0 )}$} & \multicolumn{2}{l}{ Frequency Distribution } \\
\cline { 2 - 3 } & $\mathbf{F}(\%)$ & Yes \\
\hline Wound dressing, injection, and fracture maintenance & $113(94.2 \%)$ & $7(5.8)$ \\
Assisting pregnant women in the delivery room in camps & $32(26.7)$ & $88(73.3)$ \\
First aid services & $115(95.8)$ & $5(4.2)$ \\
\hline
\end{tabular}

\section{DISCUSSION}

The present study showed that nurses working in refugees/IDPs camps in Duhok governorate have participated actively in a variety of nursing roles, including providing vaccinations, health education in the form of home visits, breastfeeding education, and general first aid services to the camp residents.

The practice of these health services is highly significant as it has been confirmed that those individuals who applied proper water and personal hygiene practices faced a lower level of diarrheal illnesses than those who did not as refugees/IDPs spend a greater part of their lives in camps before repatriation process [9]. The practices include drinking clean potable water sources piped into the home, hand washing, and sufficient soap availability.

The risk factors for the transmission of communicable diseases such as moving mass populations, resettling in temporary geographic locations, overcrowding housing, degrading economy and environment, safe potable water scarcity, poor sanitation and waste management, impoverishment, non-existent shelter, poor nutritional status, and poor access to health care interact synergistically in these complexes [10].

The present study showed high participation of the nurses in vaccinating clients in primary health centers or through home visits in accordance with national vaccination campaigns against infectious diseases. These health services are available in all primary health centers inside the camps and infants are vaccinated upon birth in the delivery room in camps or hospitals in urban areas. Those living in host communities have access to health centers in urban areas freely five days a week. It is expected that all nurses in health centers readily offer all types of vaccines as the refugees/ IDPs arrive the camps at different times.

The study showed an acceptable percentage of participation of nurses in health education activities including personal hygiene, hand washing, and women's health as reflected in the study findings. Health education was also significantly associated with health improvement. In this regard, a review study showed that hand washing is associated with a $48 \%$ reduction in diarrheal diseases [11]. In the camps, water is supplied through piped networks connected to tap stands locations. It has been documented that access to convenient water in camps is associated with hand washing activities by the camp residents [12].

A home visit is a widespread earlyintervention strategy in most developed and developing countries. The present study showed that corresponding health departments have not perceived it as a novel strategy in health status improvement as the majority of the nurses reported participating in home visits and only a minority of them have never performed home visits inside and outside the camps. The role of home-visitation programs on improving health outcome in children and families has been well documented in the literature [13-15]. 
In this study, a high percentage of nurses participated in breastfeeding education in refugee/IDPs camps. However, the remaining minority of these nurses never participated in breastfeeding education programs for pregnant women in the camps. This may be due to the fact that the majority of the nurses working in the camps simply graduated high school $(41.7 \%)$ and the Institute of nursing (40.8\%).

Breastfeeding advice is significant as the World Health Organization (WHO) has recommended breastfeeding as the optimal form of nutrition for infants' development and provides an important psychological and physiological advantage for both the mother and infant [4].

The United Nation International children's Emergency Fund (UNICEF) has estimated that 1.5 million infant deaths can be prevented annually if the infants are breastfed exclusively from birth to at least six months $[16,17]$ and lower mortality rates have been seen among those children breastfed during emergency conditions $[18,19]$. Previous evidence has shown that breastfeeding is highest among women receiving breastfeeding education [20] from these nurses[21].

The study showed that only $26.7 \%$ of nurses participated in delivery services to pregnant women. This may be due to the lack of delivery facilities in this region precluding them to have this opportunity in their nursing practice. In addition, there were only three delivery rooms in all 27 refugee/ IDPs camps.

Health promotion and education activities are achievable through interpersonal communication, group activities, and peer education and can result in positive social changes as nursing practitioners have opportunities to meet these issues through dynamic community-based approaches [22]. commitment must be made by humanitarian agencies [23] and involved in healthcare decision making, in particular, to improve women's health. [24] This can be achieved through the establishment of partnerships with community members through hiring the available refugee nurses in the camps for health improvement purposes [23] as suggested in the BRHA report as well [6]. Despite widespread health services provided to refugees and IDPs inside and outside of the camps, the BRHA reported that the majority of the health centers work part-time with few medical specialists and the centers may lack certain medications for chronic diseases.

\section{Strengths and limitations of the study}

The findings reported in the current study must be interpreted in the light of study design and reporting techniques, as the self-reporting technique does not guarantee the complete activities conducted by the nurses in the camp settings. However, to the authors' knowledge, this is the first study conducted on the nurses' role in addressing the basic health needs of refugees/IDPs in this region. The study is noteworthy as the majority of the nurses working in 26 camps of 27 available camps in Duhok governorate were included in the present study.

\section{CONCLUSIONS}

The results of the current study show that most of the nurses working in refugees/ IDPs camps in Duhok governorate have participated in infection control activities, health education campaigns, and breastfeeding education. Further studies are required to examine the effectiveness of the nurses' activities on the overall improvement of refugees/IDPs' health.

The authors suggest the related local departments and their international counterparts take advantage of the refugee nurses' skills in meeting the displaced 
individuals' health needs. In addition, nurses are the main point of contact with ill individuals in camps. Therefore, it is vital that nurses working with refugees are well equipped with sufficient knowledge, skills, and resources to deliver efficient health care of acceptable quality.

\section{CONFLICTS OF INTEREST}

The authors report no conflict of interests.

\section{REFERENCES}

[1] Ozaras, R, H Leblebicioglu, M Sunbul, F Tabak, II Balkan, M Yemisen, et al., The Syrian conflict and infectious diseases. Expert Review of Anti-Infective Therapy, 2016. 14 (6): 547-555.

[2] Zimmermann, A, J Dörschner, and F Machts, The 1951 Convention relating to the status of refugees and its 1967 protocol: A commentary. 2011: Oxford University Press.

[3] Spiegel, P, M Sheik, C Gotway-Crawford, and P Salama, Health programmes and policies associated with decreased mortality in displaced people in postemergency phase camps: a retrospective study. The Lancet, 2002. 360(9349): 1927-1934.

[4] Trends UNHCR Global, Forced Displacement in 2014. UNHCR: Geneva, Switzerland, 2016.

[5] Prüss-Üstün, A and C Corvalán, Preventing disease through healthy environments. Towards an estimate of the environmental burden of disease. Geneva: World Health Organization, 2006.

[6] BRHA, IDPs and Refugees in Duhok Governorate, Profile and General Information. 2016, Board of Relief and Humanitarian Affair Governorate of Duhok.

[7] Squires, A, Nursing's opportunity within the global refugee crisis. International Journal of Nursing Studies, 2016. 55: 1-3.

[8] Paquet, C and G Hanquet, Control of infectious diseases in refugee and displaced populations in developing countries. Bulletin de I'Institut Pasteur, 1998. 96(1): 3-14.

[9] Morris, MD, ST Popper, TC Rodwell, SK Brodine, and KC Brouwer, Healthcare barriers of refugees post-resettlement. Journal of Community Health, 2009. 34(6): 529.
[10] Connolly, MA, M Gayer, MJ Ryan, P Salama, P Spiegel, and DL Heymann, Communicable diseases in complex emergencies: impact and challenges. The Lancet, 2004. 364 (9449): 1974-1983.

[11] Cairncross, S, C Hunt, S Boisson, K Bostoen, $\checkmark$ Curtis, IC Fung, et al., Water, sanitation and hygiene for the prevention of diarrhoea. International Journal of Epidemiology, 2010. 39(suppl_1): i193-i205.

[12] Biran, A, WP Schmidt, $R$ Wright, $T$ Jones, $M$ Seshadri, P Isaac, et al., The effect of a soap promotion and hygiene education campaign on handwashing behaviour in rural India: a cluster randomised trial. Tropical Medicine \& International Health, 2009. 14(10): 13031314.

[13] Chapman, J, E Siegel, and A Cross, Home visitors and child health: analysis of selected programs. Pediatrics, 1990. 85(6): 10591068.

[14] Weiss, HB, Home visits: Necessary but not sufficient. The Future of Children, 1993: 113128.

[15] Schonberg, S, S Anderson, J Bays, P Duncan, $M$ Felice, J Frader, et al., The role of homevisitation programs in improving health outcomes for children and families. Pediatrics, 1998. 101(3 I): 486-489.

[16] Scariati, PD, LM Grummer-Strawn, and SB Fein, A Longitudinal Analysis of Infant Morbidity and the Extent of Breastfeeding in the United States. Obstetrical \& Gynecological Survey, 1998. 53(2): 73-74.

[17] Raisler, J, C Alexander, and P O'campo, Breast-feeding and infant illness: a doseresponse relationship? American Journal of Public Health, 1999. 89(1): 25-30.

[18] Molbak, K, A Gottschau, P Aaby, N Hojlyng, L Ingholt, and APJ Da Silva, Prolonged breast feeding, diarrhoeal disease, and survival of children in Guinea-Bissau. BMJ Clinical Research, 1994. 308(6941): 1403-1406.

[19] Jakobsen, M, M Sodemann, G Nylén, C Balé, J Nielsen, I Lisse, et al., Breastfeeding status as a predictor of mortality among refugee children in an emergency situation in Guinea -Bissau. Tropical Medicine \& International Health, 2003. 8(11): 992-996.

[20] Raine, P, Promoting breast-feeding in a deprived area: the influence of a peer support initiative. Health \& Social Care in the Community, 2003. 11(6): 463-469. 
[21] Madanat, H, H Farrell, R Merrill, and E Cox, Breastfeeding Education, Support, and Barriers among Iraqi Refugee Women in Jordan. International Electronic Journal of Health Education, 2007. 10: 138-149.

[22] Kimunai, E, Health promotion and education among refugee women: a literature review. Journal of Social Change, 2014. 6(1): 2.

[23] Solheim, K, Patterns of community relationship: nurses, non-governmental organizations and internally displaced persons. International Nursing Review, 2005. 52(1): 60-67.

[24] Palinkas, LA, SM Pickwell, K Brandstein, TJ Clark, LL Hill, RJ Moser, et al., The journey to wellness: stages of refugee health promotion and disease prevention. Journal of Immigrant Health, 2003. 5(1): 19-28. 